\title{
The Effect on Solubility and pH of Sodium Chloride Solution by Magnetic Field
}

\author{
${ }^{1}$ Anjali Leal, ${ }^{2}$ P. S. Tarsikka \\ ${ }^{1,2}$ Department of Mathematics, Statistics and Physics, Punjab Agricultural University, Ludhiana, India \\ Email-anjalileal0412@gmail.com
}

\begin{abstract}
On the whole world's major environmental problem is water pollution, due to pollutant water increases in microscopic harmful living organism's counts and it causes change in water odour, taste and colour, which causes the spread of dangerous epidermal diseases. A physical treatment using magnetic field it is beneficial for the medical, food industry, control and removing of the scale formation on the walls, in medical, in food industry and heating equipment's but the efficiency of this treatment is still a controversial question. In the present study, like physical parameters total dissolved salts (TDS), electrical conductivity (EC) and pH of sodium chloride solution have been evaluated under the effect of different strength of magnetic field (0.05T-0.15T) for different exposure time (3 hours, 5hours and 7 hours). The electrical conductivity and total dissolved salts rapidly increasing with the exposure of time and $\mathrm{pH}$ is increase with time as compared to control but for 3 hours is more and for 7 hour is less. Data collected during the experiment was analyzed statistically (SPSS-20.0). This analysis shows that the increase in TDS, $E C$ and $p H$ under the effect of magnetic field was significant $(p<0.05)$. The regression analysis was used to show linear relation between TDS and EC of water.
\end{abstract}

Keywords-Electrical conductivity, Hard water, Magnetic field, pH, Total dissolved salt.

\section{INTRODUCTION}

Water is essential to start and to continue the human life. It is directly related to each other. Water has spiritual values in many cultures and is associated with birth, spiritual cleansing and death. It is nutrient source and makes chemical reactions to happen. Water has unique properties it act as; solvent, an environmental, a temperature, a reactant and a molecule with cohesive properties. Use of hard water is the main problem in industry, domestic, agriculture and environmental. Scale formation is the solid deposits present in the exchanger of heat instrument and creates the heating of the hard water and makes contact with pipes and walls of the heat exchanger. Too many years used chemical method to control and remove the mineral fouling. It requires handling and disposal of hazardous chemicals, raising environmental concerns. Chlorine treatment of water is used then changes of odour, colour, hydrogen sulphide, growth of algae and germs. But due to the physical treatment it is beneficial for the control and removing of the scale formation on the walls and heating equipment's, this method is beneficial not only to the industry but also to the environment. The water treated by the magnetic field or passes through the magnetic device is called magnetized water. By the magnetic field strength change the physical and chemical properties as compared to ordinary water but not the acquired magnetic field strength. The hydrogen bond in liquid water is highly affected by magnetic field. These uncharacteristic properties of water are unique and results showed that many fluctuations of macroscopic properties Reddy et al (2014). Due to the magnetic field reduce the bond angle; these water clusters can break down but the increase solubility. The influence of magnetic field on liquid water has been deeply studied from last fifty years. To many people, magnets are complete mystery. Ibrahim (2006) study that the rate of flow is decreases with the increasing of magnetic field strengths, due to the application of magnetic field on water may also make alignment of water clusters and increasing of the magnetic field strength may also increases the alignment of water molecules. The alignment of water clusters may increase its electric current. According to (Gholizadeh et al 2008) magnetic treatment of water operates on the principle that a Lorentz force is experienced by each ion as the water is allowed to pass through a magnetic water softener. The frequency of collisions between ions increases due to redirection of the particles, positive and negative ions combine to form an insoluble compound. So, calcium carbonates dispatched from the solution as a mud which can be easily remove from the water. Musa and Hamoshi (2012) have observed that water may be levitated in very high magnetic field, which increases the tetrahedrality at the time. By the magnetic field is some disorder in the hydrogen bonding and improvement of salt mobility in hard water; the large water clusters are cut and break down to 
form smaller water clusters or twice water molecule. Hassan and Rahman (2016) observed that squeezes the bond pairs to close and deflects the bond pairs by the magnetic field then bond angle decreases from $104.5^{\circ}$ to $103^{\circ}$.The magnetic charge is lost by the existence of the metallic layer inside the pipes and then purified which flows out of the tap and is no longer magnetized (Al-Khazan et al 2011).Such a simple technology can have many beneficial impacts on industries utilizing water, truly motivates its deeps study. Thus in view of this, the present study was planned to see the effect of magnetic field at different time intervals on the electrical conductivity, total dissolved salts and $\mathrm{pH}$ of the $\mathrm{NaCl}$ solution (hard water). The study of inherent properties of hard water such as electrical conductivity, TDS and $\mathrm{pH}$ give more insight to the concept of magnetic water treatment.

\section{MATERIALS AND METHODS}

The Haritron electromagnet (Model EM-20) was used for applying magnetic field to hard water. Larger magnetic field is produced when number of coil is more. The dimensions of electromagnet are diameter $9.0 \mathrm{~cm}$ and length $27.5 \mathrm{~cm}$ with total number of turns 3000 per coil. The distance between poles of electromagnet is adjustable up to $7 \mathrm{~cm}$. The power supply of electromagnets has output voltage 0 100 volts and output current 0-10 ampere. To determine the nature of magnetic field, the magnetic field strength for different positions between the poles of electromagnet at different currents were measured by Digital gauss meter (DGM-102) to assure uniformity of field. Distilled water was prepared in the laboratory with of distillation of tap water. To study the effect of magnetic field on TDS, electrical conductivity and $\mathrm{pH}$ of hard water, at $0.05 \%$ concentrations of $\mathrm{NaCl}$ solution. For preparation of $0.05 \%$ $\mathrm{NaCl}$ solution, $0.05 \mathrm{~g}$ of sodium chloride was dissolved in small volume of distilled water. Once the sodium chloride salt dissolved completely (after swirls the flask gently if necessary), water was added to make up the final volume as $100 \mathrm{ml}$ of flask. In a similar way, other concentrations were prepared in laboratory by using distilled water. The parameters electrical conductivity and total dissolved salts of hard water were measured with the help of waterproof HANNA probe 98311 with range TDS (0-2000 ppm) and EC (0-3999 $\mu \mathrm{S} / \mathrm{cm})$. The HANNApH waterproof tester havingpH range from -2.0 to 16.0 was used to measurepH of hard water.Hard water solution stabilise for 1 day. After 1 day, take $40 \mathrm{ml}$ solution in the beaker placed in the electromagnets centre with the distance of poles. Apply the magnetic field on hard water solution for 3 hours. After 3 hour beaker out the electromagnets then HANNA $\mathrm{EC} / \mathrm{TDS} / \mathrm{pH}$ temperature meter in the solution. The $\mathrm{EC} / \mathrm{TDS} / \mathrm{pH}$ of the solution measure with variation of temperature. It is same procedure on 5 hours and 7 hours time duration. Same procedure repeated on different magnetic strength $(0.05 \mathrm{~T}, 0.15 \mathrm{~T}, 0.25 \mathrm{~T})$.

\section{RESULTS AND DISCUSSION}

\subsection{Effect of magnetic field strength on TDS and EC at different exposure time}

In this experiment measurement were made on TDS/EC of $\mathrm{NaCl}$ solution having on $0.05 \%$ concentration at different magnetic field strength $(0.05 \mathrm{~T}, 0.15 \mathrm{~T}$ and $0.25 \mathrm{~T})$ and different time intervals ( 3 hours, 5 hours and 7 hours). The plot has been shown in fig.1.1 to fig.1.6. After magnetization the solution changes the physical, chemical and microbiological properties. It has been observed that TDS/EC increases linearly with variation of temperature. The increase in electrical conductivity is more for 7 hours and less for 3 hours with exposure time for all concentrations. Which means TDS/EC depends upon time of exposure. The increase in TDS/EC with concentration is due to increase in $\mathrm{NaCl}$ ions concentration. The values of regression coefficients $a$ and $b$, its coefficient of determination $\mathrm{R}^{2}$ are given below in Table 1.1 to1.2.

Table 1.1 Regression coefficient for $E C(\mu / S)$ at different magnetic field

\begin{tabular}{|c|c|c|c|c|c|}
\hline $\begin{array}{l}\text { Concentration } \\
(\mathbf{w} / \mathbf{v})\end{array}$ & $\begin{array}{l}\text { Magnetic } \\
\text { field } \\
\text { strength }\end{array}$ & $\begin{array}{l}\text { Time } \\
\text { (hrs) }\end{array}$ & $\mathbf{a}$ & b & $\mathbf{R}^{2}$ \\
\hline \multirow{12}{*}{$0.05 \%$} & \multirow{4}{*}{$0.05 \mathrm{~T}$} & 0 & 17.651 & 481.036 & $0.999 * *$ \\
\hline & & 3 & 17.916 & 493.806 & $0.999 * *$ \\
\hline & & 5 & 17.988 & 508.130 & $0.998 * *$ \\
\hline & & 7 & 17.848 & 532.152 & $0.998 * *$ \\
\hline & \multirow{4}{*}{$0.15 \mathrm{~T}$} & 0 & 17.651 & 481.036 & $0.999 * *$ \\
\hline & & 3 & 17.874 & 494.200 & $0.999 * *$ \\
\hline & & 5 & 18.008 & 513.355 & $0.999 * *$ \\
\hline & & 7 & 18.197 & 533.530 & $0.998 * *$ \\
\hline & \multirow{4}{*}{$0.25 \mathrm{~T}$} & 0 & 17.651 & 481.036 & $0.999 * *$ \\
\hline & & 3 & 18.372 & 485.785 & $0.999 * *$ \\
\hline & & 5 & 18.842 & 497.355 & $0.998 * *$ \\
\hline & & 7 & 19.186 & 515.427 & $0.997 * *$ \\
\hline
\end{tabular}


Table 1.2 Regression coefficient for TDS ( $\mathrm{ppm}$ ) at different magnetic field

\begin{tabular}{|c|c|c|c|c|c|}
\hline $\begin{array}{l}\text { Concentration } \\
(\mathrm{w} / \mathrm{v})\end{array}$ & $\begin{array}{l}\text { Magnetic } \\
\text { field } \\
\text { strength }\end{array}$ & $\begin{array}{l}\text { Time } \\
\text { (hrs) }\end{array}$ & $\mathbf{a}$ & b & $\overline{\mathbf{R}^{2}}$ \\
\hline \multirow[t]{12}{*}{$0.05 \%$} & \multirow{4}{*}{$0.05 \mathrm{~T}$} & 0 & 8.832 & 240.170 & 0.999 ** \\
\hline & & 3 & 8.963 & 246.506 & $0.999 * *$ \\
\hline & & 5 & 8.995 & 253.927 & $0.998^{* *}$ \\
\hline & & 7 & 8.932 & 265.730 & $0.998^{* *}$ \\
\hline & \multirow[t]{4}{*}{$0.15 \mathrm{~T}$} & 0 & 8.832 & 240.170 & $0.999 * *$ \\
\hline & & 3 & 8.915 & 248.303 & $0.999 * *$ \\
\hline & & 5 & 9.020 & 256.542 & $0.999 * *$ \\
\hline & & 7 & 9.093 & 267.088 & $0.999 * *$ \\
\hline & \multirow[t]{4}{*}{$0.25 \mathrm{~T}$} & 0 & 8.832 & 240.170 & $0.999 * *$ \\
\hline & & 3 & 9.192 & 242.548 & 0.999 ** \\
\hline & & 5 & 9.414 & 248.724 & $0.998^{* * *}$ \\
\hline & & 7 & 9.586 & 257.852 & 0.997 ** \\
\hline
\end{tabular}

** Significant at $5 \%$ level of significance $(\mathrm{p}<0.05)$

The increase due to temperature is due to increase in kinetic energy of the ions. They have analyzed similar type of variation shown in Mousa et al (2008) and Pang (2013). According to Barron et al (1994) the mobility of ions in solution is increased with the increase in temperature. With the dissociation of molecules, the number of ions in solution increases on increasing the temperature. The electrical conductivity depends on these factors then an increase in the solutions temperature leads to as an increase in its electrical conductivity. Hassan et al (2016) investigated that magnetism decreases the bond angle between hydrogen and oxygen atoms within each water molecule from $104.5^{\circ}$ to $103^{\circ}$ degrees. Due to decrease in bond angle, the water molecules cluster together in groups of 6-7 rather than groups of 10-12 molecules and higher. As the cluster size decreases, consequently the absorption of water increases. Pang (2013) show that electrical conductivity of magnetized water increases with increasing the frequency of externally applied electromagnetic field and magnetized time. This is due to changes of nature of charged ions and velocity of hydrogen ions as well as the changes of polarized features under the influences of electromagnetic fields.

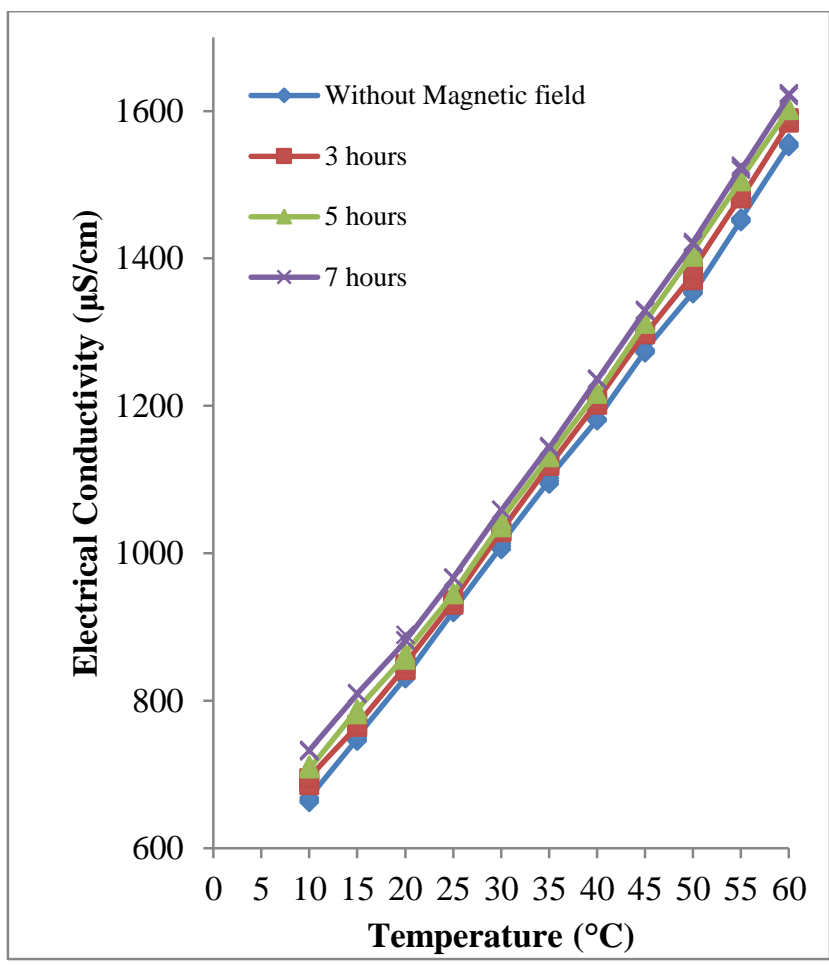

Fig.1.1Variation between the electrical conductivity and temperature for different exposure time $0.05 T$ (0.05\%)

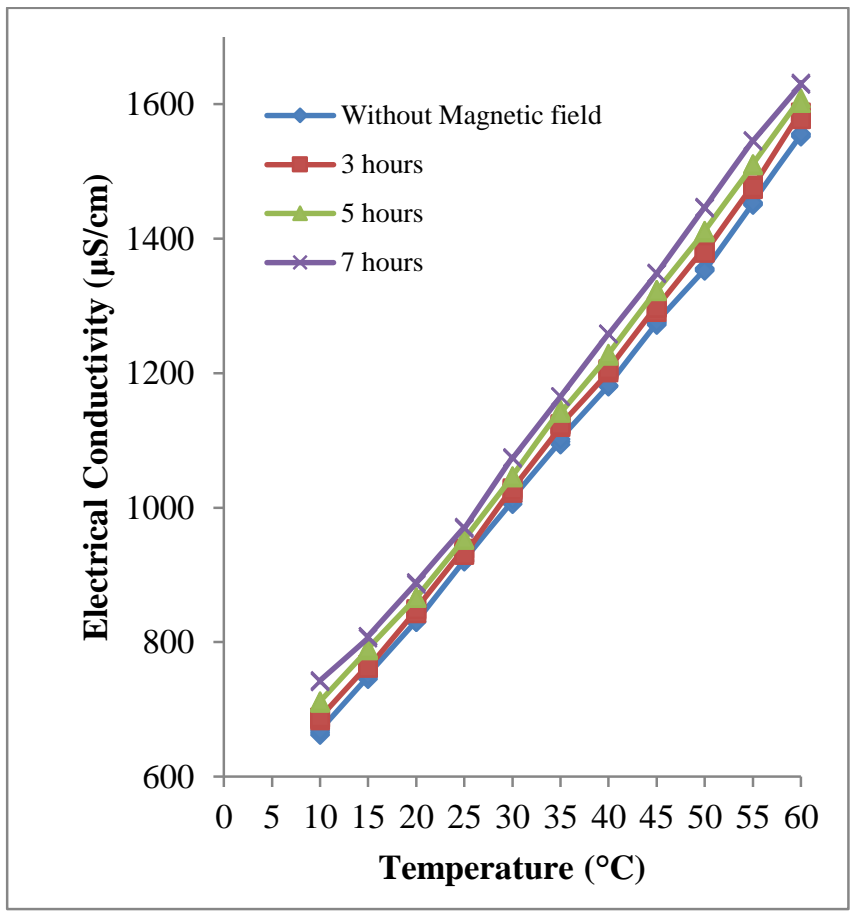

Fig. 1.2 Variation between the electrical conductivity and temperature for different exposure time $0.15 T(0.05 \%)$ 


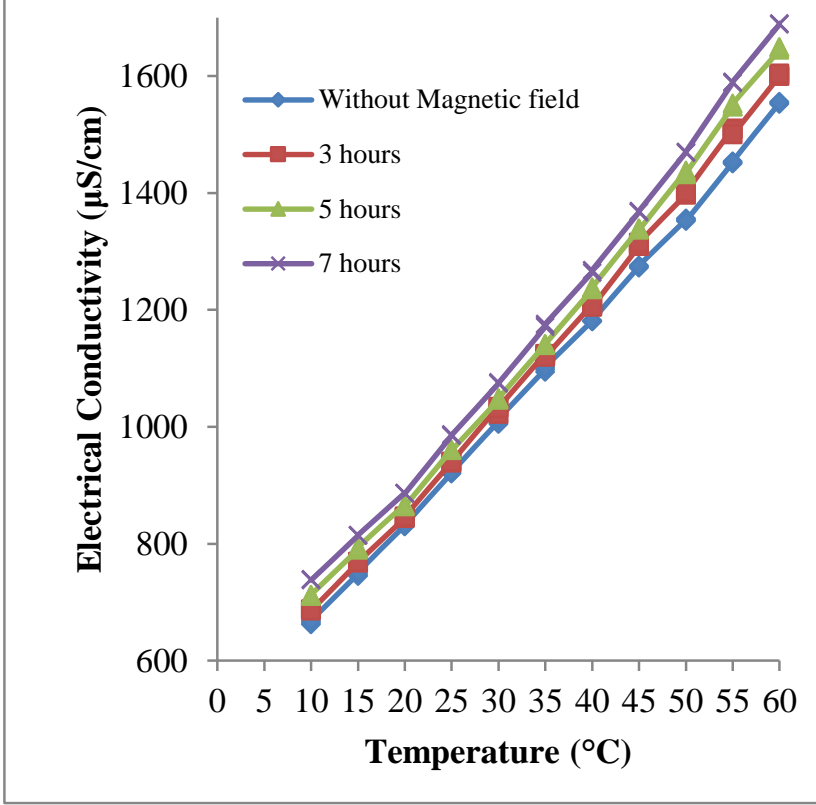

Fig.1.3 Variation between the electrical conductivity and temperature for different exposure time $0.25 T$ (0.05\%)

Moosa et al (2015) investigated that higher magnetic field strength increased the TDS. For exposing time less than 5 min, the rate of dissolving is slower than for exposing time greater than $5 \mathrm{~min}$, where rate is much greater which mean more exposure of time greater solubility of solution. While for higher field intensity the increase in TDS is very sharp.

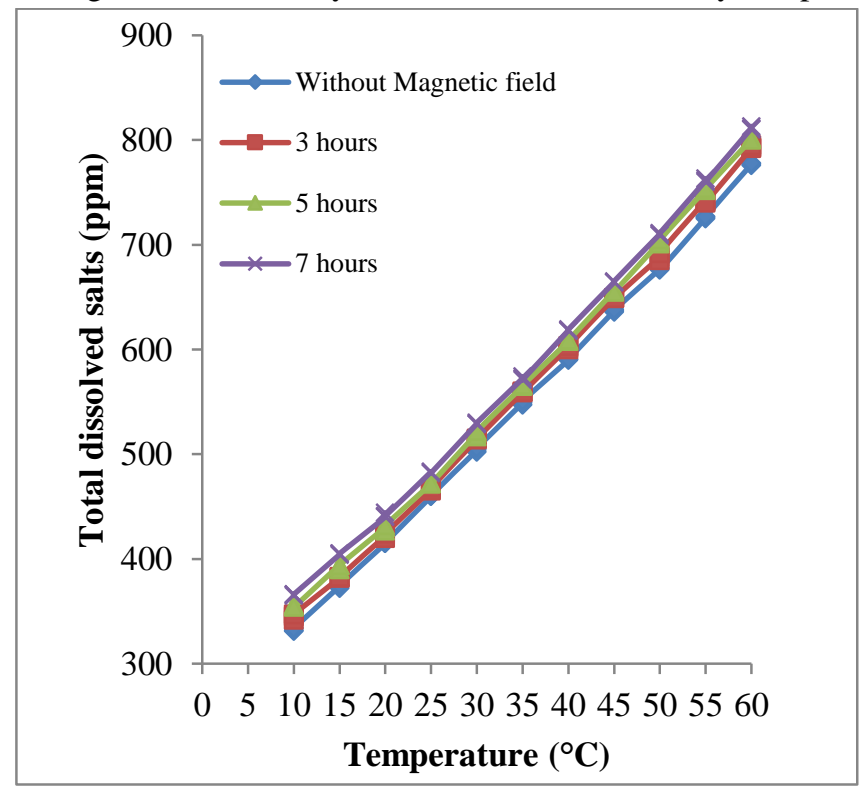

Fig.1.4 Variation between total dissolved salts and temperature for different exposure time $0.05 T$ (0.05\%)

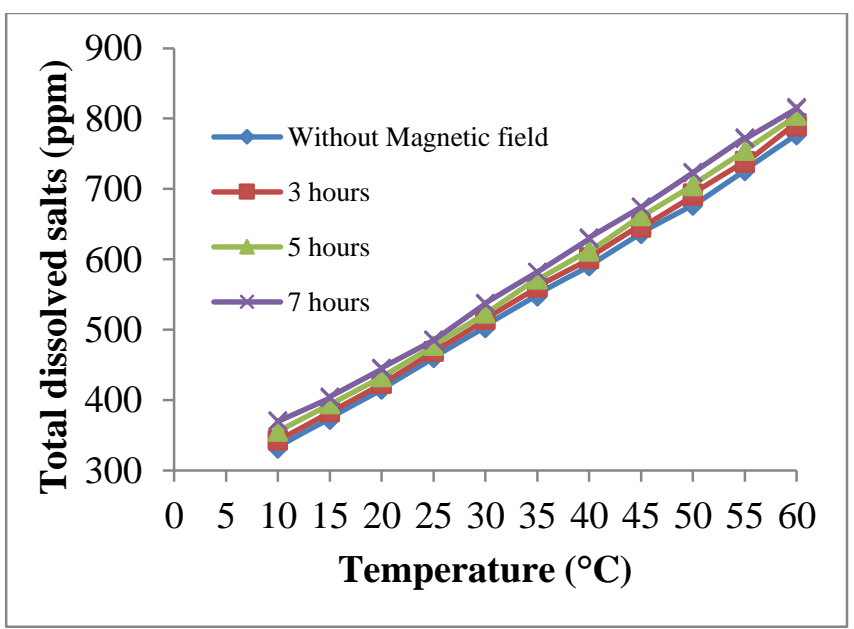

Fig. 1.5 Variation between total dissolved salts and temperature for different exposure time 0.15T (0.05\%)

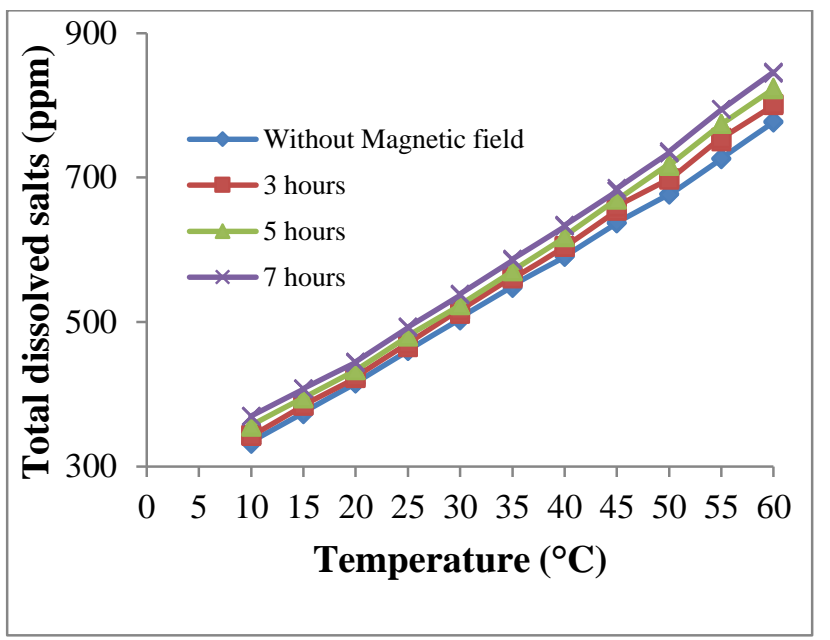

Fig. 1.6 Variation between total dissolved salts and temperature for different exposure time 0.25T (0.05\%)

\subsection{Relationship between the TDS and EC}

The relationship between electrical conductivity and total dissolved salts shown in fig.2.1. It shows linear relationship between electrical conductivity and total dissolved salts for different temperature $\left(10^{\circ} \mathrm{C}-50^{\circ} \mathrm{C}\right)$. The conductivity is directly proportional to twice of total dissolved salts. Increase in electrical conductivity with increase of temperature and magnetic field strength. A high value of electrical conductivity indicates high total dissolved salt concentration. Iyasele et al (2015) found that total dissolved salts in water; an electrical conductivity value is more. Temperature effect the electrical conductivity value increases from 2 up to $3 \%$ per 1 degree Celsius. Estimation of the electrical conductivity when number of total 
dissolved salts in solution. When conduct electrical current of water measured by electrical conductivity. Salts dissolve into positively charged ions and negatively charged ions.

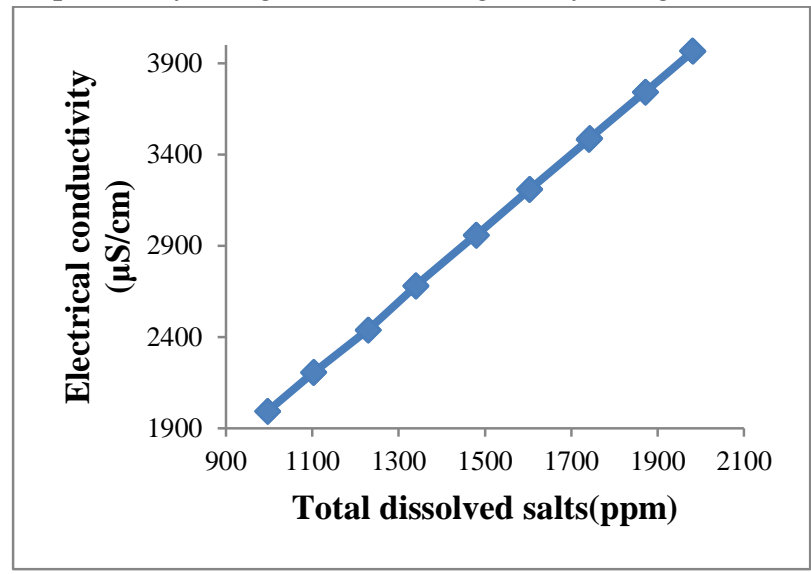

Fig.2.1 Relationship between the electrical conductivity and total dissolved salts

\subsection{Effect of magnetic field on $\mathrm{pH}$ at different exposure of time}

At $0.05 \%$ of $\mathrm{NaCl}$ solution at three different magnetic fields $(0.05 \mathrm{~T}, 0.15 \mathrm{~T}$ and $0.25 \mathrm{~T})$ for different time exposure ( 3 hours, 5 hours and 7 hours) has been shown in fig.3.1 to fig.3.3. The variation of $\mathrm{pH}$ with temperature shows smooth and regular variation. The increase in $\mathrm{pH}$ is more for higher exposure time and higher magnetic field strength at higher concentration. The $\mathrm{pH}$ of $0.05 \% \mathrm{NaCl}$ solution increases from 5.54 to 5.93 at $0.05 \mathrm{~T}$ and from 5.64 to 6.13 for $0.15 \mathrm{~T}$ field strength at $10^{\circ} \mathrm{C}$ temperature for exposure time. The $\mathrm{pH}$ of the solution change which means that there must be hydrolysis reaction happens in the solution because of ions polarization ability. Ionization reaction happens when inorganic salts dissolve in water, these ions forms. Then ions interact with $\mathrm{H}^{+}$or $\mathrm{OH}^{-}$which are form water molecules ionization. The ions with good polarization ability can bind with $\mathrm{H}^{+}$or $\mathrm{OH}^{-}$which can form weak electrolyte. Then the number of charged ion changes. This process, which is called hydrolysis reaction, promotes water hydrogen bonds breakage and breaks aqueous ionization balance.

The effect of magnetic field on $\mathrm{NaCl}$ solution is obtained to measurement of $\mathrm{pH}$. Increasing magnetic field strength then $\mathrm{pH}$ of hard water is increase as compared to untreated hard water. The separation between the exposures of time is more than magnetic field strength is increase. We have more exposure of time $\mathrm{pH}$ is decreased for different time intervals. The reason behind $\mathrm{pH}$ is decreased due to large exposure of time that acidity of $\mathrm{NaCl}$ solution increases due to the number of hydrogen bonds increase. The total dissolved salts increased by magnetic field strength then acidity of hard water are increased.

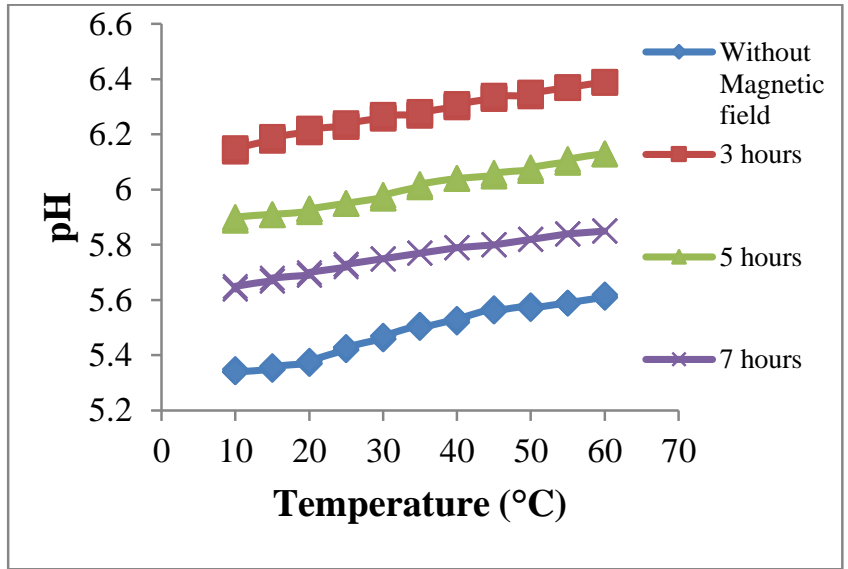

Fig. 3.1 Variation of $p H$ with temperature for at $0.05 \%$ concentration and field strength $0.05 T$

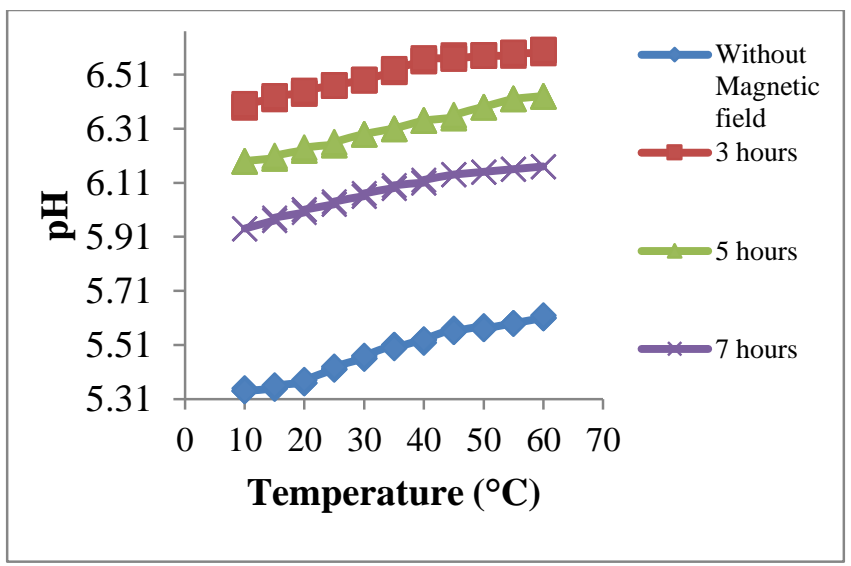

Fig. 3.2 Variation of $\mathrm{pH}$ with temperature for at $0.05 \%$ concentration and field strength $0.15 T$

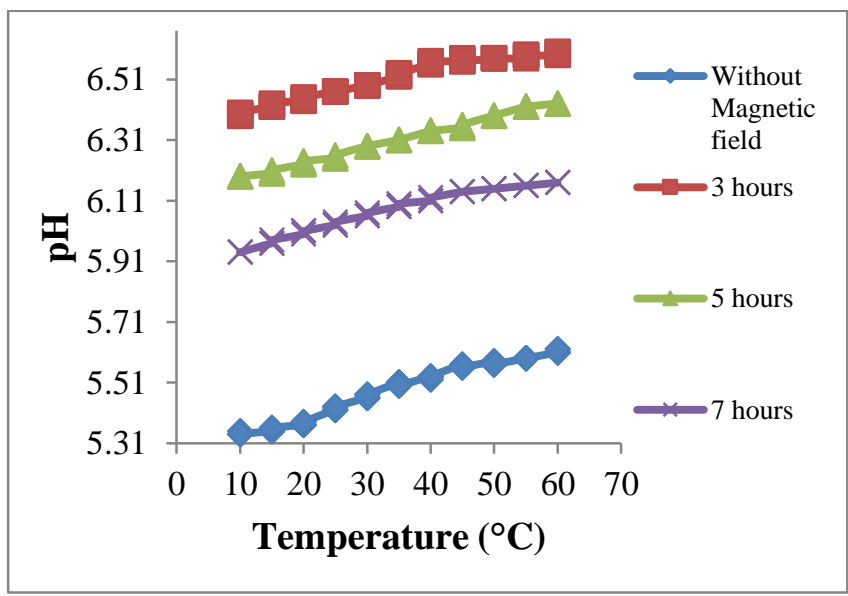

Fig.3.2: Variation of $\mathrm{pH}$ with temperature for at $0.05 \%$ concentration and field strength $0.25 T$ 
Hassan and Rahman et al (2016) reported a higher $12 \%$ increase in water $\mathrm{pH}$ after magnetization. The effect of the exposure to the magnetic field was increased $\mathrm{pH}$ of water. The effect depends on the time of exposure to the magnetic field. Moosa et al (2015) studies $\mathrm{pH}$ value increases with exposing time this is due to the decreasing in the hydrogen ion concentration, while $\mathrm{pH}$ value increases with increasing magnetic field for distilled water due to the polarization of water molecules and the decreasing of hydrogen ion concentration the water molecules will arrange in one direction.

Table.3.1: Regression coefficient for $\mathrm{pH}$ at different magnetic field

\begin{tabular}{|c|c|c|c|c|c|}
\hline $\begin{array}{l}\text { Concentration } \\
(\mathrm{w} / \mathrm{v})\end{array}$ & $\begin{array}{l}\text { Magnetic } \\
\text { field } \\
\text { strength }\end{array}$ & $\begin{array}{l}\text { Time } \\
\text { (hrs) }\end{array}$ & $\mathbf{a}$ & b & $\mathbf{R}^{2}$ \\
\hline \multirow{12}{*}{$0.05 \%$} & \multirow{4}{*}{$0.05 \mathrm{~T}$} & 0 & 0.006 & 5.278 & $0.974 * *$ \\
\hline & & 3 & 0.009 & 5.875 & $0.933^{* *}$ \\
\hline & & 5 & 0.008 & 5.683 & $0.934 * *$ \\
\hline & & 7 & 0.007 & 5.505 & $0.951^{* *}$ \\
\hline & \multirow{4}{*}{$0.15 \mathrm{~T}$} & 0 & 0.006 & 5.278 & $0.974 * *$ \\
\hline & & 3 & 0.005 & 6.111 & $0.988 * *$ \\
\hline & & 5 & 0.005 & 5.836 & $0.991 * *$ \\
\hline & & 7 & 0.004 & 5.615 & $0.982 * *$ \\
\hline & \multirow{4}{*}{$0.25 \mathrm{~T}$} & 0 & 0.006 & 5.278 & $0.974 * *$ \\
\hline & & 3 & 0.004 & 6.363 & $0.956^{* *}$ \\
\hline & & 5 & 0.005 & 6.133 & $0.994 * *$ \\
\hline & & 7 & 0.005 & 5.912 & $0.966^{* *}$ \\
\hline
\end{tabular}

** Significant at $5 \%$ level of significance $(\mathrm{p}<0.05)$

\subsection{Relationship between the $\mathrm{EC}$ and $\mathrm{pH}$}

There was a proportional relationship between the electrical conductivity records and $\mathrm{pH}$ values. It was found that the increase in $\mathrm{pH}$ value is more effective with the elevation in temperature degree. The reason behind $\mathrm{pH}$ is decreased due to large exposure of time that acidity of $\mathrm{NaCl}$ solution increases due to the number of hydrogen bonds increase. The electrical conductivity increased by magnetic field strength then acidity of hard water are increased.

\subsection{Relationship between time and TDS/EC}

The plot shown in fig 5.1 to 5.2. TDS/EC gradually increases with time at different temperature. The TDS/EC is more for $20^{\circ} \mathrm{C}$ and less for $60^{\circ} \mathrm{C}$.

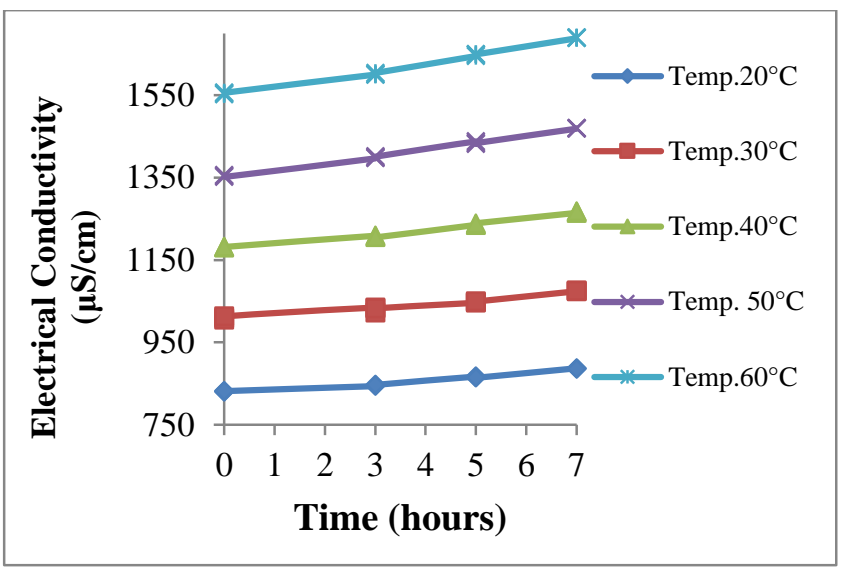

Fig. 5.1 Variation between time and EC at different temperature

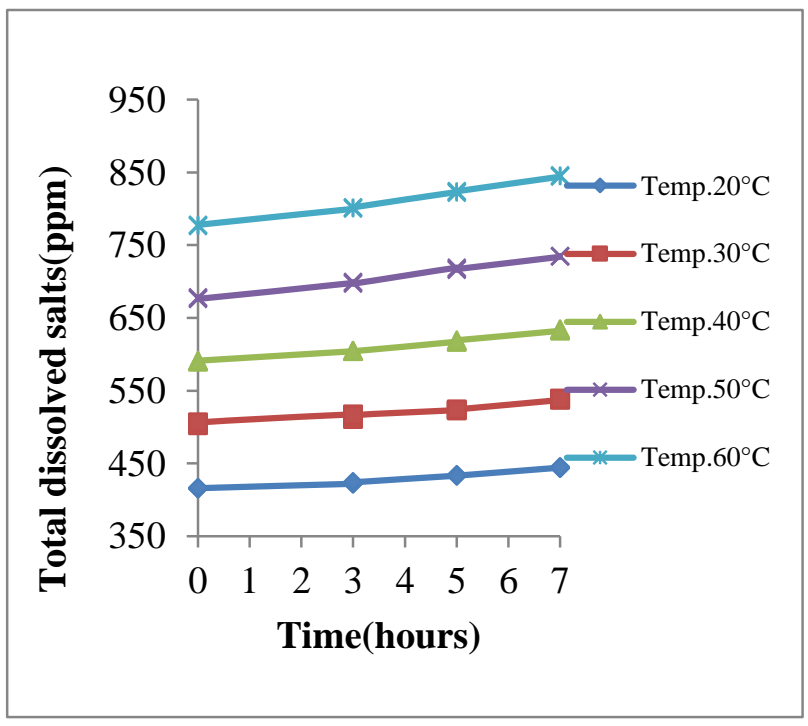

Fig.5.2 Variation between time and TDS at different temperature.

\section{CONCLUSIONS}

(i) The TDS/EC of $\mathrm{NaCl}$ solution gradually increased with different magnetic field strength at different exposure time.

(ii) The values of $\mathrm{pH}$ increase with magnetic field strength; at different exposure time but for 3 hours are more and for 7 hour are less.

(iii) The changes in total dissolved salts, electrical conductivity and $\mathrm{pH}$ of hard water under the effect of magnetic field strengths have been observed significant at $5 \%$ level of significance. 
(iv) The solubility of $\mathrm{NaCl}$ solution is increased because value of EC/TDS significantly increased by magnetic field strength.

(v) It results beneficial for removing of kidney stone and production of sea food.

\section{REFERENCES}

[1] Batoul Mohamed Abdullatif, Mulook Al-Khazan and Nabila Al-Assaf(2011). Effects of magnetically treated water on water status, chlorophyll pigments and some elements content of Jojoba (Simmondsiachinensis L.) at different growth stages. African Journal of Environmental Science and Technology (ISSN 19960786) 5(9) 722-31 10.5897/AJEST11.117.

[2] M. Gholizadeh, H. Arabshahi, M.R. Saeidi and B. Mahdavi(2008) The Effect of Magnetic Water on Growth and Quality Improvement of Poultry. MiddleEast Journal of Scientific Research (ISSN 1990-9233) 3(3) 140- 44.

[3] I. H. Ibrahim (2006) Biophysical Properties of Magnetized Distilled Water. Egypt. J. Sol. 29(2)36369.

[4] Iyasele, J.U, David J. Idiata, D.J (2015) investigation of the relationship between electrical conductivity and total dissolved solids for mono-valent, di-valent and tri valent metal compounds. International Journal of Engineering Research and Reviews (ISSN 2348697X)3(1)40-48.

[5] S. M. Hassan and Ridzwan Abdul Rahman Hassan(2016) Effects of exposure to magnetic field on water properties and hatchability of artemiasalina. Journal of Agricultural \& Biological Sciences (ISSN 1990-6145) 11(11)416-23.

[6] Dr. Gaafar M. Moosa M.Sc. Jabbar Hussain. Khulaef Ali Chaloob Khraibt Niehad Raheem Shandi Dr. Mohamed S.K Al Braich (2015) Effect of Magnetic Water on Physical Properties of Different Kind of Water, and Studying Its Ability to Dissolving Kidney Stone.Journal of Natural Sciences Research (ISSN 2224-3186) 5(18)85-94.

[7] Mousa A M and Hmed A S (2008) The Effect of Magnetic Water on Dissolving kidney Stones. Eng Tech 26(5).

[8] B. Siva Konda Reddy Dr.Vaishali G Ghorpade, Dr. H. SudarsanaRao(2014) Effect of magnetic field exposure time on workability and compressive strength of magnetic water concrete. International Journal of
Advanced Engineering Technology (ISSN 0976-3945) 4(3): 120-22.

[9] Xiao-Feng Pang and Gui-FaShens(2013) The changes of physical properties of water arising from the magnetic field and its mechanism. Mod. Phys. Lett. B 27(1)(1350228) 1-9. 